\title{
Effect of Leukocytapheresis Therapy Using a Leukocyte Removal Filter in Crohn's Disease
}

\author{
Tadashi Kosaka, Koji Sawada, Kunio Ohnishi, Akimitsu Egashira, Makoto Yamamura, \\ Noritoshi TANidA, Masamichi SATOMI and Takashi SHIMOYAMA
}

\begin{abstract}
Eighteen patients with active Crohn's disease were treated with one leukocytapheresis session per week for a five-week intensive therapy, decreasing to one leukocytapheresis session per month for five sessions of initial maintenance therapy. Nutritional indices, inflammatory reactions, flow cytometry profiles, and cytokine production were also assessed before and after the intensive and initial maintenance therapy. Nine of the patients $(50 \%)$ attained remission at the end of the intensive therapy. The nine non-remission patients had exhibited longer periods of suffering and more severely affected sites prior to the therapy. In 14 of 18 patients $(\mathbf{7 7 . 8 \%})$, the nutritional indices, Internal Organization of Inflammatory Bowel Disease (IOIBD) score and Crohn's Disease Activity Index (CDAI) improved from the pretherapy levels, but only the remission group (50\%) showed improvement in C-reactive protein (CRP) and erythrocyte sedimentation rate (ESR). The remission group showed significantly higher pretherapy $\mathrm{CD4}^{+} \mathrm{CD}^{+}{ }^{+}$cell ratios and interleukin-2 (IL-2) production than the non-remission group, and significantly lower activated cells.
\end{abstract}

(Internal Medicine 38: 102-111, 1999)

Key words: lymphocytapheresis, human leukocyte antigen (HLA)-DR, cytokine, CD4 ${ }^{+} \mathrm{CD} 45^{+}$

\section{Introduction}

Crohn's disease is an inflammatory bowel disease of unknown etiology with an increasing incidence in recent years in Japan that is thought to be related to changes in lifestyle, and in particular diet (1). In a majority of patients the onset comes at a relatively early age, and the period of suffering is long. Treatments typically involve the use of corticosteroids (2), sulphasalazine (3), and 5-aminosalicylic acid (5-ASA) (4), immunosuppressants (5), and elemental diet $(6,7)$. The disease is particularly resistant to treratment among those with intestinal stenosis, fistula, and complex anal fistulae.

Leukocytapheresis with leukocyte removal filter (LCAP) has been applied to the treatment of various diseases in recent years $(8,9)$. Since 1992 , we have used this procedure in the treatment of ulcerative colitis (with an efficacy rate in a preliminary study as high as $80 \%$ ), and also in the treatment of autoimmune diseases and fuluminant hepatitis $(9,10,11)$.

Several reports have described the application of apheresis to the treatment of Crohn's disease. Plasmapheresis (12) and T-lymphocyte apheresis by centrifugation (13) have been reported to exert antiinflammatory effects in the active stages of
Crohn's disease and to induce long-term remission, but it has also been reported that apheresis by centrifugation was found inappropriate for the long-term maintenance of remission, primarily because of the complexity and duration of sessions involving centrifugation (14).

Further studies are desirable to resolve these conflicting conclusions concerning the use and effects of centrifugation, but none have been reported, presumably in part because medication and nutritional therapy are effective in many cases for both induction and maintenance of remission and also because of the complexity involved in using centrifugation as the means of leukocyte removal.

Medication and nutritional therapies, however, are not without problems. They are often burdensome to patients because of side effects of the medications $(15,16)$ and severe restrictions of peroral diet imposed by the Crohn's disease symptoms. Alternative or additional forms of intervention are therefore desirable in many cases, to permit a better quality of life for patients with this disease.

The present study on the effects of treating Crohn's disease by LCAP was conducted with these objectives in mind. As no previous study had been performed in Japan on the use of LCAP

From the Department of Internal Medicine IV, Hyogo College of Medicine, Nishinomiya

Received for publication April 13, 1998; Accepted for publication November 16, 1998

Reprint requests should be addressed to Dr. Koji Sawada, the Department of Internal Medicine IV, Hyogo College of Medicine, 1-1 Mukogawa, Nishinomiya, Hyogo 663-8501 
for Crohn's disease, it was necessary to conduct this in the form of a preliminary study, rather than in the more desirable form of a controlled study. The filters adopted for this study were leukocyte removal filters known to remove nearly $100 \%$ of granulocytes and monocytes, 70 to $80 \%$ of lymphocytes, and 30 to $40 \%$ of platelets, but little or no red blood cells (17, 18). The protocol required long periods for both the intensive and the maintenance therapy, in view of the long term of treatment which is generally required for the control of Crohn's disease by drug therapy. Only patients currently receiving little or no drug administration were admitted into the study, to avoid interaction and confusion between the effects of the LCAP and drug therapies. Changes in clinical indices and other characteristics such as cell surface markers and cytokine production were observed, to permit as much insight as possible into the degree and nature of the effects of LCAP therapy on Crohn's disease patients.

\section{Patients and Methods}

Admission into this clinical study was limited to patients with active Crohn's disease who were currently receiving either no medication or only low-dose corticosteroids $(10 \mathrm{mg} /$ day or less) and/or salazosulfapyridine ( $3.0 \mathrm{~g} /$ day or less) and further whose conditions were not changed after the patients had been hospitalized and were treated by additional total parenteral nutrition or total elemental diets for one week. The study began in February 1993. Of the eighteen patients en- rolled, nine were male and nine female; their ages were $27.2 \pm 11.6$ years (mean $\pm S D$ ) and periods of suffering prior to enrollment were $4.5 \pm 4.1$ years. Three patients were in the first onset of Crohn's disease, and the other fifteen were in relapse. The affected sites were the small intestine in six patients, both small and large intestines in seven, and the large intestine in five. Intestinal stenosis was observed in seven patients, and anal lesions in ten. Their Internal Organization of Inflammatory Bowel Disease (IOIBD) score (19) and their Crohn's Disease Activity Index (CDAI) (20) before the LCAP therapy were $2.5 \pm 0.7$ and $231.5 \pm 56.7$, respectively. Two of the patients had been receiving $10 \mathrm{mg} /$ day of corticosteroid and two others had been receiving $3.0 \mathrm{~g} /$ day of salazosulfapyridine; the same medications were continued for these four during the LCAP therapy. A summary of the patient profiles is shown in Table 1. Informed consent was received from each patient before enrollment in this study.

LCAP was performed with a Plasauto 1,000 apheresis system (Asahi Medical Co. Ltd., Tokyo) (8) equipped with a Cellsorba leukocyte removal filter (Asahi Medical Co.) $(8,9$, 18). Whole blood was taken from a cubital or femoral vein, passed through the filter, and returned to a corresponding vein. Intensive therapy consisted of one LCAP session per week for five weeks (9), and was followed by initial maintenance therapy consisting of five sessions of LCAP at intervals decreasing in accordance with the patient's condition to as low as about once every four weeks. In each LCAP session, 3 liters of whole blood were processed at a blood rate of $50 \mathrm{ml} / \mathrm{min}$. Nafamostat

Table 1. Initial Clinical Profiles of Patients in Remission and Non-remission Groups

\begin{tabular}{|c|c|c|}
\hline & Remission ( $\mathrm{n}=9$ ) & Non-remission $(n=9)$ \\
\hline Age (year) & $20.6 \pm 6.0$ & $33.9 \pm 12.3^{*}$ \\
\hline $\operatorname{Sex}(M / F)$ & $5 / 4$ & $4 / 5$ \\
\hline Prior suffering (years) & $2.9 \pm 3.9$ & $6.0 \pm 3.9 *$ \\
\hline \multicolumn{3}{|l|}{ Affected site } \\
\hline Ileal type & 4 & 2 \\
\hline Ileocolical type & 2 & 5 \\
\hline Colical type & 3 & 2 \\
\hline \multicolumn{3}{|l|}{ Complication } \\
\hline Stenosis & 1 & $6^{+}$ \\
\hline Anal lesion & 4 & 6 \\
\hline \multicolumn{3}{|l|}{ Drugs } \\
\hline Steroids & 0 & 2 \\
\hline Sulphasalazine & 0 & 2 \\
\hline \multicolumn{3}{|l|}{ Mode of nutritional intake } \\
\hline total parenteral nutrition & 8 & 9 \\
\hline elemental diet nutrition & 1 & 0 \\
\hline peroral nutrition & 0 & 0 \\
\hline $\begin{array}{l}\text { Mean total calorie intake } \\
\qquad(\mathrm{kcal})\end{array}$ & $\begin{array}{c}1,800 \\
(38.3 \mathrm{kcal} / \mathrm{kg})\end{array}$ & $\begin{array}{c}1,800 \\
(40 \mathrm{kcal} / \mathrm{kg})\end{array}$ \\
\hline
\end{tabular}

Group placement was made at end of intensive LCAP therapy; and years of prior suffering are given as mean $\pm \mathrm{SD} ;{ }^{*} \mathrm{p}<0.05$ by chi-square test, ${ }^{+} \mathrm{p}<0.05$ by generalized Wilcoxon's test. 
mesilate (Torii Pharmaceutical Co., Tokyo) was used as the anti-coagulant (19).

The clinical and biochemical assessments and barium enema and/or endoscopic evalutions reported here, unless otherwise specifically stated, were made before and after the five LCAP sessions of the intensive and initial maintenance therapy. Follow-up maintenance therapy, also consisting essentially of one LCAP session approximately every four weeks, was continued two years or more to investigate the long-term effects, for all patients, except for those who showed no clinical improvement at the end of the initial maintenance therapy or who were otherwise necessarily removed from the study.

The nutritional indices, inflammatory reactions, flow cytometry profiles, and cytokine production reported here, unless otherwise specifically stated, were determined before and after the intensive therapy and after the initial maintenance therapy. The nutritional indices were ideal body weight ratio (\%IBW), hemoglobin, serum total protein and cholesterol. Inflammatory reactions were assessed in terms of leukocyte count, C-reactive protein (CRP), and erythrocyte sedimentation rate (ESR).

Remission was defined as the fulfillment of the Japanese criteria for Crohn's disease remission, which require scores within the normal range for all three of the following IOIBD score (zero or one), CRP $(0.3 \mathrm{mg} / \mathrm{dl}$ or lower), and ESR (15 $\mathrm{mm} / \mathrm{h}$ or lower). The CDAI was also calculated (21), for reference and comparison with the IOIBD scores.

Flow cytometry was performed with the Ortho Spectrum III Laser Flow cytometry system (22), for determination of the proportions of $\mathrm{CD}^{+}, \mathrm{CD}^{+}, \mathrm{CD}^{+}, \mathrm{CD} 38^{+}, \mathrm{CD}^{2} 6^{+}$, human leukocyte antigen (HLA)-DR ${ }^{+}, \mathrm{HLADR}^{+} \mathrm{CD}^{+}, \mathrm{HLADR}^{+} \mathrm{CD} 4^{+}$, $\mathrm{HLADR}^{+} \mathrm{CD} 8^{+}, \mathrm{CD} 4{ }^{+} \mathrm{CD} 29^{+}\left(\mathrm{CD} 4{ }^{+} \mathrm{B} 4^{+}\right), \mathrm{CD}^{+}{ }^{+} \mathrm{CD} 45 \mathrm{RA}^{+}$ $\left(\mathrm{CD} 4^{+} 2 \mathrm{H} 4^{+}\right), \mathrm{CD} 11 \mathrm{a}^{+} \mathrm{CD} 8^{+}, \mathrm{CD} 11 \mathrm{~b}^{+} \mathrm{CD} 8^{+}, \mathrm{TCR} \gamma-\delta$ and $\mathrm{NK}$ cells as well as $\mathrm{CD} 4 / 8$ and $\mathrm{HLADR}^{+} \mathrm{CD} 4 / 8$ rations. Cytokine production was examined in terms of interleukin (IL)-1 $\beta$, IL2, IL-4, IL-6, IL-8, TNF $\alpha$ and IFN $\gamma$.

The production of IL- $1 \beta$ and IL- 8 was determined by their measurement in monocyte supernatant with lipopolysaccharide (final concentration $1.5 \mu \mathrm{g} / \mathrm{ml}$ ), and that of IL-2, IL-4, IL6 , tumor necrosis factor (TNF) $\alpha$, and interferon (IFN) $\gamma$ by their measurement in mononuclear cell supernatant with concanavalin A (final concentration $3 \mu \mathrm{g} / \mathrm{ml}$ ) as mitogen after a 24-h incubation.

Statistical significance was defined by the attainment of a p-value of less than 0.05 by the chi-square test or by the generalized Wilcoxon's test, in comparisons between the remission $(\mathrm{R})$ and non-remission $(\mathrm{N})$ groups and between each group before and after the intensive and initial maintenance therapies.

\section{Results}

\section{Outcome of treatment}

The success rate for the intensive therapy, as the proportion of patients having achieved remission by the Japanese standard criteria at the end of the intensive therapy, was nine of eighteen patients and thus 50\%, as shown in Table 1.

Four of the patients who had total parenteral nutrition in the $\mathrm{N}$ group were removed from the study at the end of the intensive therapy, and thus received no LCAP maintenance therapy. None of these four showed improvement in symptoms. One who had bleeding of small intestine before the initiation of LCAP had exacerbated bleeding and two who had intestinal stenosis before LCAP showed no improvement in either anal fistulae or intestinal stenosis, and surgical removal of bleeding or stenosis lesions was indicated for all three. For the fourth, routine abdominal ultrasound examination after completion of the intensive therapy showed signs of pancreatic cancer, even though the other laboratory data, including bile duct enzyme, bilirubin, and tumor markers, did not suggest its presence. The diagnosis of pancreatic cancer was cofirmed by further imaging studies including computerized tomography, angiography, and endoscopic retrograde cholangiopancreatography, and surgery was indicated for pancreatic cancer. For the purposes of the present analysis, this patient was nevertheless classified as non-remission, and thus in the $\mathrm{N}$ group, because his stenosis lesion was clearly distinguishable from the pancreatic tumor lesion and showed no improvement or amelioration in related tenderness at the end of the intensive therapy.

In the course of the follow-up maintenance therapy, one patient in the $\mathrm{R}$ group relapsed. No other relapse occurred either in the initial maintenance period or in the follow-up maintenance period of LCAP sessions approximately once every four weeks for a mean period of about 43 months for all eight of the patients in the $\mathrm{R}$ group who remained free from relapse. The five patients in the $\mathrm{N}$ group were removed at the end of the 5 sessions of the maintenance therapy because of no further improvement. Four out of these five patients deteriorated within 6 months after completion of the intensive therapy and were admitted again to hospital. Surgical removal of stenosis lesion was indicated for two patients. Another two patients were under total parenteral nutrition (TPN) again and then complete elemental diet (ED) therapy was used for maintenance nutrition. The latest success rate as determined by the standard Japanese criteria for Crohn's disease, after a mean period of about 43 months of follow-up maintenance therapy, was thus $44 \%$ ( 8 of 18 patients).

As shown in Table 2, the $\mathrm{R}$ group showed significant improvement in IOIBD score, CRP, and ESR at the end of both the intensive therapy and the initial maintenance therapy, with mean values for this group all reaching and remaining within the normal range, while the $\mathrm{N}$ group showed significant improvement only in IOIBD score and did not achieve mean values within the normal range for any of these three parameters. As also shown, the mean IOIBD scores before the intensive therapy were significantly lower for the $\mathrm{R}$ group than for the $\mathrm{N}$ group. It should be noted that all of the values shown here and elsewhere in this report for the $\mathrm{N}$ group following the initial maintenance therapy represent only five of the original nine patients in this group, due to the removal of the other four from the study.

As also shown in Table 2, the results were less clear on the 
Leukocytapheresis for Crohn's Disease

Table 2. Inflammatory Reactions, IOIBD, and CDAI before and after LCAP Intensive and Initial Maintenance Therapies, for Remission ( $R$ ) and Non-remission (N) Groups

\begin{tabular}{ccccc}
\hline \multirow{2}{*}{$\begin{array}{c}\text { parameter } \\
\text { (normal range) }\end{array}$} & Group & before LCAP & \multicolumn{2}{c}{ after } \\
\cline { 4 - 5 } & & & Intensive LCAP & Maintenance LCAP \\
\hline WBC & $\mathrm{R}$ & $7,177 \pm 2,476$ & $5,602 \pm 2,192^{*}$ & $6,477 \pm 2,149^{+}$ \\
$\left(5,000-8,000 \mathrm{~mm}^{3}\right)$ & $\mathrm{N}$ & $7,278 \pm 1,819$ & $6,550 \pm 1,415$ & $8,920 \pm 7,002$ \\
$\mathrm{CRP}$ & $\mathrm{R}$ & $2.7 \pm 5.9$ & $0.2 \pm 0.1^{*, .}$ & $0.2 \pm 0.12^{+, \$}$ \\
$(<0.3 \mathrm{mg} / \mathrm{dl})$ & $\mathrm{N}$ & $3.3 \pm 3.8$ & $2.1 \pm 2.2$ & $2.7 \pm 2.1$ \\
$\mathrm{ESR}$ & $\mathrm{R}$ & $33 \pm 35$ & $13 \pm 2^{*, \$}$ & $10 \pm 5^{+, s}$ \\
$(<15 \mathrm{~mm} / 1 \mathrm{~h})$ & $\mathrm{N}$ & $33 \pm 38$ & $46 \pm 26$ & $58 \pm 24$ \\
IOIBD & $\mathrm{R}$ & $1.8 \pm 1.5^{\$}$ & $0.7 \pm 0.3^{*}$ & $0.8 \pm 0.2^{++}$ \\
$(0$ or 1$)$ & $\mathrm{N}$ & $3.0 \pm 2.3$ & $1.7 \pm 1.2^{*}$ & $1.0 \pm 1.3^{*+,}$ \\
CDAI & $\mathrm{R}$ & $227.0 \pm 62.1$ & $92.4 \pm 7.4^{* *}$ & $93.0 \pm 7.0^{* *}$ \\
$(<150)$ & $\mathrm{N}$ & $234.3 \pm 2.3$ & $94.6 \pm 10.9^{* *}$ & $91.4 \pm 11.5^{* *}$ \\
\hline
\end{tabular}

LCAP (leukocytapheresis), All data shown are mean \pm SD for nine patients in each group, or for five patients in the $\mathrm{N}$ group for the initial maintenance therapy; WBC: white blood cell, CRP: C-reactive protein, ESR: erythrocyte sedimentation rate, IOIBD: international organization for the study of inflammatory bowel disease score, CDAI: Crohn's disease activity index. Statistical comparisons: * after intensive or initial maintenance LCAP vs. before LCAP; ${ }^{+}$after intensive LCAP vs. after initial maintenance LCAP; ${ }^{\$} \mathrm{R}$ group vs. $\mathrm{N}$ group; single $\left({ }^{*,+,}\right)$ and double $\left({ }^{* *,++, \$}\right)$ superscripts denote $\mathrm{p}<0.05$ and $\mathrm{p}<0.01$ by generalized Wilcoxon's test, respectively.

basis of the mean CDAI values obtained for the two groups. They showed significant improvement for both groups after the intensive and maintenance therapies, to within the normal range of less than 150 , and no significant difference between the two groups either before the intensive therapy or after the intensive and maintenance therapies. The decrease in CDAI was apparently the result of the alleviation of symptoms such as diarrhea, abdominal pain, and fever which was observed in almost all of the patients of the $\mathrm{N}$ group as well as all in the $\mathrm{R}$ group, and a primary cause of the divergence between the CDAI and IOIBD scores was apparently the inclusion of abdominal tenderness in the latter but not the former.

\section{Side effects}

During the intensive therapy, there were very few side effects except bleeding in one of the 18 patients, however, there were some side effects (6.4\%: 21/328 procedures) including digestive symptoms such as abdominal discomfort and nausea, allergic reactions such as extremity itch, sensory disturbance of tongue and lips, and nasal obstruction, cardiac symptoms of palpitations, neurological reactions such as mild headache and dizziness, and general reactions such as slight fever and chill during the maintenance therapy. All side effects were mild and temporary. All of these side effects were alleviated when the anticoagulant was changed. Some patients had several concommitant adverse symptoms.

\section{Mode of nutritional intake}

For the nine patients in the $\mathrm{R}$ group, the numbers receiving total parenteral, elemental, and peroral nutrition (less than 20 $\mathrm{g}$ /day fat restricted diet), respectively, were eight, one, and zero and mean total calorie intake was $1,800 \mathrm{kcal}(38.3 \mathrm{kcal} / \mathrm{kg})$ before the intensive therapy. However, the number and mean total calorie intake were changed to one, five, and three and approximately $1,750 \mathrm{kcal}$ (about $35.2 \mathrm{kcal} / \mathrm{kg}$ ) at the end of the intensive therapy and zero, three, and six and approximately $1,720 \mathrm{kcal}$ (about $34.5 \mathrm{kcal} / \mathrm{kg}$ ) at the end of the initial maintenance therapy. In the $\mathrm{N}$ group, the corresponding numbers and mean total calorie intake were nine, zero, and zero and 1,800 $\mathrm{kcal}(40 \mathrm{kcal} / \mathrm{kg})$; five, four, and zero and $1,800 \mathrm{kcal}(39.5 \mathrm{kcal} /$ $\mathrm{kg}$ ); and one, four, and zero and $1,800 \mathrm{kcal}(38.3 \mathrm{kcal} / \mathrm{kg})$. At the time of their removal from the study, one of the patients requiring surgery for stenosis lesion was on total parenteral nutrition and the other two were on elemental diet, and the patient requiring surgery for pancreatic cancer was on total parenteral nutrition.

\section{Age, prior history, and affected sites}

The $\mathrm{R}$ group showed a statistically lower $(\mathrm{p}<0.05)$ mean age, period of prior suffering, and incidence of intestinal stenosis than the $\mathrm{N}$ group, as shown in Table 1 . There was no statistical difference between the two groups in relation to affected sites or anal fistulae.

\section{Inflammatory reactions and nutritional indices}

The related results are summarized in Tables 2 and 3. As noted above, both CRP and ESR decreased significantly in the intensive therapy and remained at normal levels after the initial maintenance therapy in the $\mathrm{R}$ group, whereas the $\mathrm{N}$ group showed no significant improvement in any of the inflammatory reaction indicators at any time.

Total protein and albumin levels were within the normal 
Table 3. Nutritional Indices before and after LCAP Intensive and Initial Maintenance Therapies, for Remission (R) and Non-remission (N) Groups

\begin{tabular}{|c|c|c|c|c|}
\hline \multirow{2}{*}{$\begin{array}{c}\text { Parameter } \\
\text { (normal range) }\end{array}$} & \multirow{2}{*}{ Group } & \multirow{2}{*}{ before LCAP } & \multicolumn{2}{|c|}{ after } \\
\hline & & & Intensive LCAP & Maintenance LCAP \\
\hline \multirow{2}{*}{$\begin{array}{l}\text { \%Ideal Body wt. } \\
\qquad(85-115 \%)\end{array}$} & $\mathrm{R}$ & $90.5 \pm 11.6$ & $94.6 \pm 10.9^{* *}$ & $97.4 \pm 11.5^{*}$ \\
\hline & $\mathrm{N}$ & $90.2 \pm 9.0$ & $92.4 \pm 7.4^{*}$ & $94.9 \pm 7.0^{*}$ \\
\hline \multirow{2}{*}{$\begin{array}{l}\text { Total protein } \\
(6.5-8.3 \mathrm{~g} / \mathrm{dl})\end{array}$} & $\mathrm{R}$ & $6.7 \pm 0.8$ & $6.7 \pm 0.5$ & $7.3 \pm 0.5^{*,++}$ \\
\hline & $\mathrm{N}$ & $6.9 \pm 0.5$ & $6.8 \pm 0.7$ & $7.1 \pm 0.9$ \\
\hline \multirow{2}{*}{$\begin{array}{c}\text { Albumin } \\
(3.5-5.0 \mathrm{~g} / \mathrm{dl})\end{array}$} & $\mathrm{R}$ & $3.9 \pm 0.4$ & $4.0 \pm 0.2$ & $4.2 \pm 0.2^{*,+}$ \\
\hline & $\mathrm{N}$ & $3.6 \pm 0.4$ & $3.6 \pm 0.5$ & $3.8 \pm 0.6$ \\
\hline \multirow{2}{*}{$\begin{array}{l}\text { Hemoglobin } \\
(12.0-16.5 \mathrm{~g} / \mathrm{dl})\end{array}$} & $\mathrm{R}$ & $11.8 \pm 2.7$ & $11.9 \pm 1.6$ & $12.9 \pm 2.3$ \\
\hline & $\mathrm{N}$ & $11.9 \pm 1.7$ & $11.2 \pm 1.1$ & $11.2 \pm 2.4$ \\
\hline \multirow{2}{*}{$\begin{array}{c}\text { Cholesterol } \\
(130-220 \mathrm{mg} / \mathrm{dl})\end{array}$} & $\mathrm{R}$ & $123 \pm 31$ & $129 \pm 39$ & $146 \pm 20^{*}$ \\
\hline & $\mathrm{N}$ & $138 \pm 39$ & $127 \pm 33$ & $154 \pm 36$ \\
\hline
\end{tabular}

LCAP: leukocytapheresis, wt.: weight, All data shown are mean \pm SD for nine patients in each group, or for five patients in the $\mathrm{N}$ group for the initial maintenance therapy. Statistical comparisons: * after intensive or initial maintenance LCAP vs. before LCAP; ${ }^{+}$after intensive LCAP vs. after initial maintenance LCAP; ${ }^{\$} \mathrm{R}$ group vs. $\mathrm{N}$ group; single $\left(^{*+, \$}\right)$ and double $\left({ }^{* *,++, \$ \$}\right)$ superscripts denote $\mathrm{p}<0.05$ and $\mathrm{p}<0.01$ by generalized Wilcoxon's test, respectively.

range for both groups throughout the study, but did show significant increases after the initial maintenance therapy in the $\mathrm{R}$ group. The IBW percentage was also within the normal range throughout the study for both groups, but showed a significant increase after the intensive therapy and a further significant increase after the initial maintenance therapy. The hemoglobin level was below normal in both groups prior to therapy, and rose to the normal range in the $\mathrm{R}$ group but not the $\mathrm{N}$ group after the initial maintenance therapy. Serum cholesterol was low before in the $\mathrm{R}$ group, but had risen to the normal range by the end of the initial maintenance therapy; in the $\mathrm{N}$ group it was at or near normal throughout the study.

\section{Flow cytometry and cytokines}

The results are summarized in Tables 4 and 5. The "control" values used in this study were the reference values obtained for healthy volunteers as described by the supplier of the measurement materials. As shown in Table 4, the mean values for all of the cell surface marker ratios except that of $\mathrm{HLADR}^{+} \mathrm{CD}^{+}$ were within the control range throughout the study in the $\mathrm{R}$ group and the proportion of the $\mathrm{CD} 4{ }^{+} \mathrm{CD} 45 \mathrm{RA}^{+}$cells was relatively high before the LCAP therapy and increased throughout the study. In the $\mathrm{N}$ group, the mean values were above the control range for $\mathrm{HLADR}^{+}, \mathrm{HLADR}^{+} \mathrm{CD}^{+}$, and $\mathrm{HLADR}^{+} \mathrm{CD} 8^{+}$ but within the control range for $\mathrm{HLADR}^{+} \mathrm{CD}^{+}, \mathrm{CD}^{+} \mathrm{CD} 29^{+}$, and $\mathrm{CD} 4^{+} \mathrm{CD} 45 \mathrm{RA}^{+}$throughout the study, and had decreased to the control range for $\mathrm{HLADR}^{+} \mathrm{CD}^{+}$at the end of the initial maintenance therapy.

Significant differences between the two groups include higher mean ratios for the $\mathrm{N}$ group than the $\mathrm{R}$ group in $\mathrm{HLADR}^{+} \mathrm{CD}^{+}$cells before and after the intensive therapy but not after the initial maintenance therapy, and in $\mathrm{HLADR}^{+} \mathrm{CD} 4^{+}$ and $\mathrm{CD} 4{ }^{+} \mathrm{CD} 29^{+}$cells before the intensive therapy and after the initial maitenance therapy. In contrast, the proportion of $\mathrm{CD}^{+}{ }^{+} \mathrm{CD} 45 \mathrm{RA}^{+}$cells was significantly lower for the $\mathrm{N}$ group than for the $\mathrm{R}$ group throughtout the study. For both groups, the proportions of $\mathrm{CD}^{+}, \mathrm{CD}^{+}, \mathrm{CD} 8^{+}, \mathrm{CD} 38^{+}, \mathrm{CD} 56^{+}$, and $\mathrm{CD} 11 \mathrm{a}^{+} \mathrm{CD} 8^{+}$cells, the levels of TCR $\gamma-\delta$ and NK activity, and thd $\mathrm{CD} 4 / 8$ and $\mathrm{HLADR}{ }^{+} \mathrm{CD} 4 / 8$ ratios remained within the control range and showed no significant differences throughout the study (data not shown).

As shown in Table 5, the cytokine measurements showed relatively large deviations from the mean for both groups throughout the study. In both groups, the mean levels were within the control range for IL- $1 \beta$ and above the control range for IL- 6 and TNF $\alpha$, with no significant differences between the groups or between different stages of the therapy. For IL-2, the mean level was high in the R group before therapy but decreased gradually and was within the control range after the initial maintenance therapy, while in the $\mathrm{N}$ group it was within the control range throughout the study, though significantly lower than that of the $\mathrm{R}$ group at the initiation and at the end of the intensive therapy. For IL-4, the pre-therapy levels were both within the control range but had decreased below that range in the $\mathrm{N}$ group after intensive therapy and in both groups after the initial maintenance therapy. For IL-8, the level was within the control range throughout the study in the $\mathrm{R}$ group, while in the $\mathrm{N}$ group it was initially below the control range but had in- 
Leukocytapheresis for Crohn's Disease

Table 4. Flow Cytometry Profiles before and after LCAP Intensive and Initial Maintenance Therapies, for Remission (R) and Non-remission (N) Groups

\begin{tabular}{|c|c|c|c|c|}
\hline \multirow{2}{*}{$\begin{array}{c}\text { Parameter } \\
\text { (normal range) }\end{array}$} & \multirow{2}{*}{ Group } & \multirow{2}{*}{ before LCAP } & \multicolumn{2}{|c|}{ after } \\
\hline & & & Intensive LCAP & Maintenance LCAP \\
\hline $\mathrm{CD}^{+}+$ & $\mathrm{R}$ & $34.2 \pm 11.0$ & $36.7 \pm 9.9$ & $37.5 \pm 9.6$ \\
\hline$(25-56 \%)$ & $\mathrm{N}$ & $37.2 \pm 8.8$ & $36.7 \pm 6.4$ & $38.7 \pm 4.8$ \\
\hline $\mathrm{CD} 8^{+}$ & $\mathrm{R}$ & $39.2 \pm 9.6^{\mathrm{s}}$ & $36.2 \pm 4.3$ & $39.8 \pm 11.9$ \\
\hline$(17-44 \%)$ & $\mathrm{N}$ & $39.8 \pm 6.4$ & $34.8 \pm 4.5$ & $35.6 \pm 6.9$ \\
\hline $\mathrm{HLADR}^{+}$ & $\mathrm{R}$ & $23.5 \pm 6.7^{\$}$ & $24.7 \pm 6.8$ & $23.3 \pm 8.1^{\$}$ \\
\hline$(8-32 \%)$ & $\mathrm{N}$ & $38.3 \pm 13.3$ & $37.3 \pm 16.9$ & $35.2 \pm 5.4$ \\
\hline $\mathrm{HLADR}^{+} \mathrm{CD}^{+}{ }^{+}$ & $\mathrm{R}$ & $14.4 \pm 6.9^{\$}$ & $15.8 \pm 4.9^{\$}$ & $16.6 \pm 10.2$ \\
\hline$(8 \%<)$ & $\mathrm{N}$ & $23.8 \pm 10.7$ & $21.3 \pm 7.8$ & $16.2 \pm 6.6$ \\
\hline $\mathrm{HLADR}^{+} \mathrm{CD} 4^{+}$ & $\mathrm{R}$ & $2.7 \pm 0.8^{\$}$ & $3.2 \pm 1.1$ & $2.9 \pm 0.8^{\S}$ \\
\hline$(6 \%<)$ & $\mathrm{N}$ & $5.2 \pm 2.3$ & $5.6 \pm 2.8$ & $4.4 \pm 3.3$ \\
\hline $\mathrm{HLADR}^{+} \mathrm{CD} 8^{+}$ & $\mathrm{R}$ & $7.2 \pm 5.6$ & $7.4 \pm 3.1$ & $7.7 \pm 7.9$ \\
\hline$(10 \%<)$ & $\mathrm{N}$ & $12.5 \pm 6.1$ & $11.3 \pm 5.4$ & $7.8 \pm 9.5$ \\
\hline $\mathrm{CD} 4^{+} \mathrm{CD} 29^{+}$ & $\mathrm{R}$ & $18.3 \pm 4.2^{\$}$ & $18.9 \pm 2.7$ & $18.3 \pm 3.3^{\$ \$}$ \\
\hline$(12-36 \%)$ & $\mathrm{N}$ & $26.4 \pm 9.5$ & $24.1 \pm 8.5$ & $28.5 \pm 2.0$ \\
\hline $\mathrm{CD}^{+}{ }^{+} \mathrm{CD} 45 \mathrm{RA}^{+}$ & $\mathrm{R}$ & $18.2 \pm 9.2^{\S}$ & $20.4 \pm 8.1^{*, \$}$ & $24.5 \pm 9.3^{*+, \$}$ \\
\hline$(8-37 \%)$ & $\mathrm{N}$ & $12.7 \pm 4.1$ & $10.9 \pm 5.6$ & $12.8 \pm 4.0$ \\
\hline
\end{tabular}

LCAP: leukocytapheresis, HLA: human leukocyte antigen, All data shown are mean \pm SD for nine patients in each group, or for five patients in the $\mathrm{N}$ group for the initial maintenance therapy. Statistical comparisons: * after intensive or initial maintenance LCAP vs. before LCAP; ${ }^{+}$after intensive LCAP vs. after initial maintenance LCAP; ${ }^{\$} \mathrm{R}$ group vs. $\mathrm{N}$ group; single $\left({ }^{*+,}\right.$, and double $(* *,++\$ \$)$ superscripts denote $\mathrm{p}<0.05$ and $\mathrm{p}<0.01$ by generalized Wilcoxon's test, respectively.

creased to the range after both the intensive and initial maintenance therapy. For IFN $\gamma$, the level was âbove the control range throughout the study in the $\mathrm{N}$ group, but in the $\mathrm{R}$ group, the high levels before and after intensive treatment had decreased to the control range at the end of the initial maintenance therapy.

\section{Discussion}

The etiology of Crohn's disease is not known, and symptomatic therapy is central to its treatment. Remission can be induced through total parenteral nutrition among patients without intestinal stenosis or complex anal fistulae (7), and maintained for long periods with a combination of dietary intervention or elemental diet with steroids, sulphasalazine, 5-ASA, immunosuppressants (2-6). Relapse is an ever present possibility, however, and many patients must repeatedly undergo surgical procedures for intestinal stenosis, fistula, and complex anal fistulae (15), making repeated hospitalization necessary and impeding the maintenance of ordinary life $(23,24)$.

For ulcerative colitis and other diseases, LCAP therapy with a leukocyte removal filter has been used with success by Sawada and his colleagues since 1992 (8-10). In this therapy, the leukocyte adhesion is directed toward the removal of leukocytes including activated granulocytes, monocytes, and cytotoxic Tcells, and thus toward stopping abnormal intercellular transmissions and immune reactions. It has been found effective in the induction of remission in more than $80 \%$ of patients with ulcerative colitis (9) in the preliminary study, and its efficacy in the treatment of this disease is being examined in a large clinical trial conducted by the Research Group for Inflammatory Bowel Diseases under the auspices of the Ministry of Health and Welfare of Japan (25).

The present study was a preliminary investigation on the effects of LCAP with a leukocyte removasl filter in 18 patients with active Crohn's disease. The success rate, based on the standard Japanese criteria for Crohn's disease remission, was 50\% after the intensive and initial maintenance therapies and $44 \%$ after the follow-up maintenance therapy, and most of the nine patients who did not achieve remission by this standard nevertheless showed amelioration in symptoms such as diarrhea, 
KosAKa et al

Table 5. Flow Cytometry Profiles before and after LCAP Intensive and Initial Maintenance Therapies, for Remission (R) and Non-remission (N) Groups

\begin{tabular}{|c|c|c|c|c|}
\hline \multirow{2}{*}{$\begin{array}{c}\text { Parameter } \\
\text { (normal range) }\end{array}$} & \multirow{2}{*}{ Group } & \multirow{2}{*}{ before LCAP } & \multicolumn{2}{|c|}{ after } \\
\hline & & & Intensive LCAP & Maintenance LCAP \\
\hline IL-1 beta & $\mathrm{R}$ & $6,457 \pm 4,524$ & $5,240 \pm 2,025$ & $8,536 \pm 12,887$ \\
\hline$(6,000-11,000 \mathrm{pg} / \mathrm{ml})$ & $\mathrm{N}$ & $11,071 \pm 19,753$ & $9,427 \pm 9,085$ & $10,350 \pm 7,462$ \\
\hline IL-2 & $\mathrm{R}$ & $11.2 \pm 6.2^{\$}$ & $9.9 \pm 5.4^{\$}$ & $5.8 \pm 4.6^{*,+}$ \\
\hline$(5.0-8.0 \mathrm{U} / \mathrm{ml})$ & $\mathrm{N}$ & $7.5 \pm 5.3$ & $5.3 \pm 3.4$ & $6.9 \pm 8.5$ \\
\hline IL-4 & $\mathrm{R}$ & $7.2 \pm 4.5$ & $6.4 \pm 6.1$ & $5.7 \pm 2.7 *$ \\
\hline$(6.0-15.0 \mathrm{pg} / \mathrm{ml})$ & $\mathrm{N}$ & $6.6 \pm 3.9$ & $3.0 \pm 1.4^{\$}$ & $3.8 \pm 1.5^{*}$ \\
\hline IL-6 & $\mathrm{R}$ & $46,400 \pm 29,336$ & $49,962 \pm 25,901$ & $74,380 \pm 75,159$ \\
\hline$(23,000-38,000 \mathrm{pg} / \mathrm{ml})$ & $\mathrm{N}$ & $43,284 \pm 26,062$ & $67,065 \pm 45,923$ & $44,041 \pm 38,447$ \\
\hline IL-8 & $\mathrm{R}$ & $201,600 \pm 102,901^{\$}$ & $226,343 \pm 176,886$ & $241,643 \pm 163,237$ \\
\hline$(140,000-330,000 \mathrm{pg} / \mathrm{ml})$ & $\mathrm{N}$ & $104,663 \pm 61,455$ & $195,833 \pm 156,593$ & $289,625 \pm 328,531$ \\
\hline TMF alfa & $\mathrm{R}$ & $2,549 \pm 1,303$ & $2,588 \pm 1,103$ & $3,801 \pm 2,620$ \\
\hline$(700-1,600 \mathrm{pg} / \mathrm{ml})$ & $\mathrm{N}$ & $3,085 \pm 2,160$ & $3,501 \pm 1,537$ & $3,025 \pm 1,097$ \\
\hline IFN gamma & $\mathrm{R}$ & $47.2 \pm 33.2$ & $46.0 \pm 29.4$ & $27.8 \pm 21.0^{*,+\$}$ \\
\hline$(13-31 \mathrm{IU} / \mathrm{ml})$ & $\mathrm{N}$ & $54.2 \pm 44.3$ & $53.2 \pm 56.7$ & $63.2 \pm 40.1$ \\
\hline
\end{tabular}

LCAP: leukocytapheresis, IL: interleukin, TNF: tumor necrosis factor, IFN: interferon, All data shown are mean \pm SD for nine patients in each group, or for five patients in the $\mathrm{N}$ group for the initial maintenance therapy. Statistical comparisons: * after intensive or initial maintenance LCAP vs. before LCAP; ${ }^{+}$after intensive LCAP vs. after initial maintenance LCAP; $\$$ R group vs. N group; single $(*,+\$)$ and double $(* *,+, \$$ ) superscripts denote $\mathrm{p}<0.05$ and $\mathrm{p}<0.01$ by generalized Wilcoxon's test respectively.

abdominal pain, and fever after the intensive and maintenance therapies.

Bicks and Groshart (13) have reported that treatment of Crohn's disease by T-lymphocyte apheresis with centrifugation resulted in remission for 48 of 54 patients (89\%), in which the basic criteria of remission were freedom from steroid medication and continuous function in day-to-day life. By these criteria, the rate of remission in the present study would be 14 of 18 patients, or $77.8 \%$, and thus similar to that obtained by Bicks and Groshart (13).

Comparison between the rersults of the LCAP therapy in the present study and the patient backgrounds showed the therapy to be most effective in treating Crohn's disease in cases where the period prior to suffering was relatively short and intestinal stenosis was absent. We also treated the patients with stenotic lesions and/or anal lesion by LCAP because we thought that symptoms associated with stenosis would be improved if swelling of the stenotic and anal lesions would be settled by LCAP; however, LCAP was not effective in treating the patients with stenotic and/or anal lesions. In the $\mathrm{R}$ group, three patients were given a fat-restricted diet (fat is less than $20 \mathrm{~g} /$ day) and were treated with only LCAP therapy without drugs or elemental diet. Their condition has been good for years so far and image studies such as endoscopic and X-ray examinations have shown continuous healing of both ulcers and aphthoid lesions, and no deterioration. The image studies of the $\mathrm{R}$ group are characterized by no stenosis and no fistula. Ulcers and aphthoid lesions have disappeared and have not appeared for an average period of 43 months. We think it seems that stenotic lesions, anal lesions and fistula require surgery.

In addition, LCAP treatment may be a risk for a CD patient with intestinal bleeding, though LCAP was effective for the treatment of ulcerative colitis patients who had bleeding from colonic ulcer. It may be related to the fact that the CD ulcer is usually deeper than that of UC. All side effects had eliminated when the anticoagulant was changed so that we presume that they were associated with an allergic reaction against the anticoagulant. This is in accord with other findings on the antiinflammatory effects of treating active-stage Crohn's disease with apheresis by centrifugation (12-14). It should be noted, however, that another report concluded that centrifugal apheresis would not be appropriate for maintenance of remission (14).

With the LCAP therapy, the mean IOIBD score and mean CDAI improved for both the remission (R) and non-remission (N) patient groups. A statistical difference was found between the pre-therapy IOIBD scores, but not the pre-therapy CDAI 


\section{Leukocytapheresis for Crohn's Disease}

values, of the $\mathrm{R}$ group and the $\mathrm{N}$ group. The main source of this divergence between the two scoring systems was apparently the inclusion of abdominal tenderness as a criterion in IOIBD but not in CDAI. The number of patients who had complained of abdominal tenderness before the LCAP therapy was higher in the $\mathrm{N}$ group than in the $\mathrm{R}$ group. The points of tenderness on the abdomen almost always coincided with severe intestinal lesions with stenosis. The results thus also suggest that the LCAP therapy may not fully stabilize the inflammatory reaction in patients with intestinal stenosis.

The leukocyte removal filter used in this study has been shown to be capable to remove from whole blood nearly $100 \%$ of its granulocytes and monocytes, 70 to $80 \%$ of its lymphocytes, and 30 to $40 \%$ of its platelets, but virtually no red blood cells $(17,18)$. The procedure with the leukocyte removal filter is much simpler and shorter than centrifugation, as the white blood cells are removed by their characteristic adhesion to nonwoven polyester fibers during their passage through the fiber, with no need for further processing or specializẹd equipment, and the procedure is completed in about one hour, or one-third of the time required with centrifugation. These characteristics facilitate its use in long-term maintenance therapy with minimal adverse effects $(9,10,18)$.

The results of the cytometric analysis showed several noteworthy differences between the $\mathrm{R}$ and $\mathrm{N}$ groups, particularly in the initial values and trends of the $\mathrm{HLADR}^{+}, \mathrm{HLADR}^{+} \mathrm{CD}^{+}$, $\mathrm{HLADR}^{+} \mathrm{CD} 4^{+}, \mathrm{CD} 4{ }^{+} \mathrm{CD} 29^{+}, \mathrm{CD}^{+}{ }^{+} \mathrm{CD} 45 \mathrm{RA}^{+}$cells ratios. $\mathrm{HLADR}^{+}$cells are thought to be related to activated leukocytes, $\mathrm{HLADR}^{+} \mathrm{CD}^{+}$cells to activated T-cells, and $\mathrm{HLADR}^{+} \mathrm{CD}^{+}$ and $\mathrm{CD} 4^{+} \mathrm{CD} 29^{+}$cells to activated helper $\mathrm{T}$ cells and helperinducer T-cells $(26,27)$, respectively, and $\mathrm{CD}^{+}{ }^{+} \mathrm{CD} 45 \mathrm{RA}^{+}$cells to suppresser-inducer T-cells (28). The ratio of $\mathrm{HLADR}^{+} \mathrm{CD}^{+}$ and $\mathrm{HLADR}^{+} \mathrm{CD} 8^{+}$cells decreased to near normal range with the improvement of patients' symptoms when these ratios were extremely high, which concurs with the earlier results of the preliminary $\mathrm{UC}$ study. However, $\mathrm{HLADR}^{+} \mathrm{CD}^{+}$was never in the normal range for $\mathrm{UC}$ or $\mathrm{CD}$. In the $\mathrm{UC}$ treatment, there was a tendency for LCAP to be effective for patients with a relatively high ratio of $\mathrm{HLADR}^{+} \mathrm{CD}^{+}$and $\mathrm{HLADR}^{+} \mathrm{CD}^{+}$cells and had little effect on other patients. This suggests that the ratio of the activated cells does not need to be high in UC when the inflammation of colonic mucosa and submucosa has already ceased with fibrosis. In $\mathrm{CD}$, on the other hand, even if one intestinal lesion has ceased with fibrosis, other skipped lesions would be the next target for inflammation. Because the pathology of CD is different from UC and lesions may exist in all digestive organs, especially gastrointestine, as a form of skipped lesions in $C D$, patients with a higher ratio of activated cells might have a higher pathogenic influence. Thus, these patients may form more stenotic lesions and fistula. Therefore, we should treat such patients in the early stage of $C D$ with more frequent LCAP sessions or a larger treatment volume.

Even though the proportions of $\mathrm{HLADR}^{+} \mathrm{CD}^{+}$and $\mathrm{HLADR}^{+} \mathrm{CD} 8^{+}$cells, which are involved in the activation of $\mathrm{T}$ cells (26-28), were all initially higher in the $\mathrm{N}$ group than those in the R group, still several showed some tendency to decrease during the intensive and/or maintenance therapy. However, there were no remission in the $\mathrm{N}$ group and such changes were not observed in the $\mathrm{R}$ group. The proportion of the $\mathrm{CD} 4{ }^{+} \mathrm{CD} 45 \mathrm{RA}^{+}$ cells was initially lower in the $\mathrm{N}$ group than in the $\mathrm{R}$ group and remained unchanged throughout the study, though it was relatively high before the LCAP therapy and increased throughout the study in the R group. This suggests that LCAP enhanced the immune modulating effect of the suppresser-inducer T-cells in the $\mathrm{R}$ group and not in the $\mathrm{N}$ group.

The assays for cytokine activity indicated that, in the $\mathrm{R}$ group but not the $\mathrm{N}$ group, the production of IL-2 and IFN $\gamma$ as a representative for proinflammatory cytokines was significantly lower after the initial maintenance therapy than it had been prior to the therapy, suggesting that the increased suppresserinducer T-cells function affects the proinflammatory cytokine production decrease.

In the $\mathrm{N}$ group, the production of IL-4 was significantly lower after the intensive therapy than before and the production in both groups was relatively low. The production of IL-6 and TNF $\alpha$ was higher than the control value throughout the treatment periods in both groups, despite the successful induction of remission in the R group. This shows that CD's immune abnormality is an imbalance of Th1 and Th2 functions. These changes in surface markers and cytokines are in accord with other studies on Crohn's disease $(29,30)$. IL-2 is involved in activation and multiplication of Th1 and cytotoxic T-cells (31). Also, IL-4 is involved in the activation of Th2 cells and the suppression of Th1 cells and macrophage function (32). The activation of Th2 and the repression of Th1 is thought to be involved in immune-tolerance (33). IL-6 promotes the chemotaxis of neutrophils and T-cells, and induction of adhesion factors (34). TNF $\alpha$ promotes activation of neutrophils, interstitial cells and endothelial cells, and IFN $\gamma$ promotes activation of Th1 cells, macrophages, class II major histocompatibility complex (MHC) and adhesion molecules (31).

The results of these analyses may provide some insight on the relationship between these cell types and cytokines and the effectiveness of LCAP therapy in treating Crohn's disease. The therapeutic effect of LCAP may be in part the result of its gradual decrease in the number of memory-retaining cells attacking the intestines. The decreased proportion of HLADR ${ }^{+}$ cells, the increased proportion of $\mathrm{CD}^{+}{ }^{+} \mathrm{CD} 45 \mathrm{RA}^{+}$cells, and decreased cytokine production of the cytokines IL-2 and IFN $\gamma$ are apparently associated with the mechanism of LCAP efficacy. LCAP may have the effect of stabilizing intestinal inflammation by suppressing the Th1-predominated excessive immune reaction in Crohn's disease, and it may also exhibit an immune modulating effect in cases involving excessive immune reaction. In other words, it may be able to neutralize not only the excess activated Th1, but also the activated Th2 immune reaction in cases where it exists. The results also indicate that the initial values of the proportion of activated cells, in terms of $\mathrm{HLADR}^{+}$and $\mathrm{HLADR}^{+} \mathrm{CD} 8^{+}$cell ratios and the $\mathrm{CD} 4^{+} \mathrm{CD} 29^{+} /$ $\mathrm{CD}^{+}{ }^{+} \mathrm{CD} 45 \mathrm{RA}^{+}$cell ratio, and those of IL-2 cytokine production, may be used to predict the LCAP efficacy. In the same light, the results of the immunological evaluations performed 
in the present study may be found to be more accurate indicators of the differences in patient background than the Japanese standard criteria for Crohn's disease remission.

The clinical results showed that the LCAP therapy, like Tlymphocyte apheresis, can improve patient tolerance for nutritional intake and ameliorate the related symptoms. We initially provided total parenteral nutrition together with this treatment for all patients except one, who was on a total elemental diet, due to the severity of their symptoms (i. e., severe abdominal pain and/or severe diarrhea after eating). As their clinical symptoms improved in the course of the LCAP therapy, we changed the mode of nutrition from total parenteral nutrition to total elemental diet or peroral meals, and from total elemental diet to peroral meals. Even after the frequency of the LCAP therapy was reduced from once a week to once a month in the initial maintenance therapy, eight out of nine patients in the R group needed no additional medications such as corticosteroid, salazosulfapyridine, and 5-ASA. At the time of writing, these eight patients are still receiving the LCAP therapy once a month; six of them remain able to eat orally without any symptoms, and the other two take about one-third of their total calories (approximately 1,900 kcal, $38.7 \mathrm{kcal} / \mathrm{kg}$ ) orally and two-thirds by elemental diet because of previous bouts of inflammatory reaction such as CRP and ESR increase followed by abdominal pain or diarrhea when they were attempting complete dependence on daily peroral meals. These eight patients in the $\mathrm{R}$ group have now maintained remission as defined under the Japanese criteria for an average period of about 43 months.

We fully agree with the conclusion of Bicks and Groshart (13) that apheresis can ameliorate patient symptoms and reduce the steroid dosage or eliminate the need for corticosteroids in long-term treatment of many patients suffering from Crohn's disease, and thus substantially improve the quality of life for the patient. We believe, further, that the technique of apheresis applied in the present study has an immune modulating effect similar in degree to that obtained by Bicks and Groshart (13), even though it removes only $1.6 \times 10^{10}$ of white blood cells, vs. the removal of 4 to $8 \times 10^{10}$ by the centrifugal technique of their study.

Fibrosis and intestinal stenosis are often observed in patients suffering from persistent Crohn's disease. In these patients, due to the continuous provision of antigen from intestinal tissue, there may be persistent tissue damage and a vicious circle may eventually arise between increasing immune activity and degradation of the immune response mechanism. Presumably, this vicious circle has not yet developed in patients with as yet relatively short periods of suffering, and it may be that in such patients the LCAP treatment is capable of modulating the feedback function controlling cytotoxicity.

It is widely known that total parenteral nutrition and total elemental diets can stabilize the intestinal inflammation attributed to Crohn's disease, due to the fact that they eliminate some of the contents of the ordinary oral diet from contact with the intestine. It is this contact that is thought to be the primary cause of the inflammation of the intestine or at least one of the secondary aggregating factors. In practice, however, the natu- ral urges of appetite make it difficult to refrain from the normal oral intake of food.

Improvement in the nutritional indices was observed in the respondents of the LCAP therapy in this study, which indicates that their absorption of nutritious elements improved as inflammation of the mucosa subsided. Accordingly, 6 of the 9 patients who achieved remission were able to begin and continue long-term peroral diets whilst receiving the maintenance regimen of once-monthly LCAP therapy. It is, therefore, respectfully submitted that this treatment can contribute to improving the quality of life of many patients suffering from Crohn's disease, and that the present results clearly justify the commencement of a controlled study to examine the efficacy of LCAP therapy at least in an appropriate subgroup of patients with Crohn's disease.

\section{Reference}

1) Morita N, Toki $S$, Hirohashi $T$, et al. Incidence and prevalence of inflammatory bowel disease in Japan: Nationwide epidemiological survey during the year 1991. J Gastroenterol 30 Suppl 8: 1-4, 1995.

2) Summers RW, Switz DM, Sessions JT Jr, et al. National cooperative Crohn's disease study: Results of drug treatment. Gastroenterology 77: 847-869, 1979.

3) Das KM, Dubin R. Clinical pharmacokinetics of sulphasalazine. Clin Pharmacokinet 1: 406-425, 1976.

4) Rasmussen SN, Binder V, Maier K, et al. Treatment of Crohn's disease with peroral 5-aminosalicylic acid. Gastroenterology 85: 1350-1353, 1983.

5) Brooke BN, Cave DR, King DW. Place of azathioprine for Crohn's disease. Lancet 1: 1041-1042, 1976.

6) Fischer JE, Foster GS, Abel RM, Abbott WM, Ryan JA. Hyperalimentation as primary therapy for inflammatory bowel disease. Am J Surg 125: 165$175,1973$.

7) Hirakawa H, Fukuda Y, Tanida N, Hosomi M, Shimoyama T. Home elemental enteral hyperalimentation (HEEH) for the maintenance of remission in patients with Crohn's disease. Gastroenterol Jpn 28: 379-384, 1993.

8) Sawada K, Malchesky PS, Nosé Y. Available removal systems: State of the art. Curr Stud Hematol Blood Transfus 57: 51-113, 1990.

9) Sawada K, Ohnishi K, Fukui S, et al. Leukocytapheresis therapy, performed with leukocyte removal filter, for inflammatory bowel disease. J Gastroenterol 30: 322-329, 1995.

10) Amano $K$, Fujimoto $K$, Amano $K$, et al. Filter leukapheresis and immune related disease. Jpn J Apheresis 13: 61-64, 1994.

11) Sawada K. Ohnishi K, Kosaka T, et al. Exacerbated autoimmune hepatitis successfully treated with leukocytapheresis and bilirubin adsorption therapy. J Gastroenterol 32: 689-695, 1997.

12) Holdstock GE, Fisher JA, Hamblin TJ, Loehry C. Plasmapheresis in Crohn's disease. Digestion 19: 197-201, 1979.

13) Bicks RO, Groshart KD. The current status of T-lymphocyte apheresis (TLA) treatment of Crohn's disease. J Clin Gastroenterol 11: 136-138, 1989.

14) Lerebours E, Bussel A, Modigliani R, et al. Treatment of Crohn's disease by lymphocyte apheresis: A randomized controlled trial. Grouped Etudes Therapeutiques des Affections Inflammatoires Digestives. Gastroenterology 107: 357-361, 1994.

15) Singleton JW, Law DH, Kelley ML Jr, Mekhjian HS, Sturdevant RA. National Cooperative Crohn's Disease Study: Adverse reactions to study drugs. Gastroenterology 77: 870-882, 1979.

16) Hawthorne $A B$, Hawkey $C J$. Immunosuppressive drugs in inflammatory bowel disease. A review of their mechanisms of efficacy and place in therapy. Drugs 38: 267-288, 1989.

17) Takenaka Y. Lymphocytapheresis. Artif Organs 20: 914-916, 1996. 


\section{Leukocytapheresis for Crohn's Disease}

18) Sawada K, Ohnishi K, Kosaka T, et al. Leukocytapheresis with leukocyte removal filter as new therapy for ulcerative colitis. Therapeutic Apheresis 1: 207-211, 1997.

19) de Dombal FT, Softley A, and International Organization for the Study of Inflammatory Bowel Disease. IOIBD report no 1: Observer variation in calculating indices of severity and activity in Crohn's disease. Gut $\mathbf{2 8}$ : 474-481, 1987.

20) Winship DH, Summers RW, Singleton JW, et al. National Cooperative Crohn's Disease Study: Study design and conduct of the study. Gastroenterology 77: 829-842, 1979.

21) Aoyama T, Ino Y, Ozeki M, et al. Pharmacological studies of FUT-175, nafamostat mesilate. I. Inhibition of protease activity in in vitro and in vivo experiments. Jpn J Pharmacol 35: 203-227, 1984.

22) Ip SH, Rittershaus CW, Healey KW, Struzzieiro CC, Hoffman RA, Hansen PW. Rapid enumeration of T lymphocytes by a flow-cytometric immunofluorescence method. Clin Chem 28: 1905-1909. 1982.

23) Irvine EJ, Feagan B, Rochon J, et al. Canadian Crohn's Relapse Prevention Trial Study Group. Quality of life: a valid and reliable measure of therapeutic efficacy in the treatment of inflammatory bowel disease. Gastroenterology 106: 287-296, 1994.

24) Gazzard BG. The quality of life in Crohn's disease. Gut 28: 378-381, 1987 (editorial).

25) Sawada K, Kosaka T, Shimoyama T, et al. Leukocytapheresis therapy with leukocyte removal filter for inflammatory bowel disease: Annual report of the Research Committee of Inflammatory Bowel Disease: The Ministry of Health and Welfare of Japan. 238-241, 1994.

26) Van Wauwe JP, Goossens J, Van Nyen G. Inhibition of lymphocyte proliferation by monoclonal antibody directed against the $\mathrm{T} 3$ antigen on human T cells. Cell Immunol 86: 525-534, 1984.
27) Bettens F, Walker C, Gauchat JF, Gauchat D, Wyss T, Pichler WJ. Gauchat Lymphokine gene expression related to CD4 T cell subset (CD45R/ CDw29) phenotype conversion. Eur J Immunol 19: 1569-1574, 1989.

28) Groux H, Huet S, Valentin H, Pham D, Bernard A. Suppressor effects and cyclic AMP accumulation by the CD29 molecule of $\mathrm{CD} 4^{+}$lymphocytes. Nature 339: 152-154, 1989.

29) Riethmuller G, Rieber EP, Kiefersauer S, et al. From antilymphocyte serum to therapeutic monoclonal antibodies: first experiences with a chimeric CD4 antibody in the treatment of autoimmune disease. Immunol Rev 129: 81-104, 1992.

30) Emmrich J, Seyfarth M, Fleig WE, Emmrich F. Treatment of inflammatory bowel disease with anti-CD4 monoclonal antibody. Lancet 338: 570 571, 1991 (letter).

31) Gajewski TF, Joyce J, Fitch FW. Antiproliferative effect of IFN-gamma in immune regulation. III. Differential selection of TH1 and TH2 murine helper T lymphocyte clones using recombinant IL-2 and recombinant IFNgamma. J Immunol 143: 15-22, 1989.

32) Cherwinski HM, Schumacher JH, Brown KD, Mosmann TR. Two types of mouse helper T cell clone. III. Further differences in lymphokine synthesis between Th1 and Th2 clones revealed by RNA hybridization, functionally monospecific bioassays, and monoclonal antibodies. J Exp Med 166: 1229-1244, 1987.

33) Mosmann TR, Cherwinski H, Bond MW, Giedlin MA, Coffman RL. Two types of murine helper T cell clone. I. Definition according to profiles of lymphokine activities and secreted proteins. J Immunol 136: 2348-2357, 1986.

34) Kopf M, Baumann H, Freer G, et al. Impaired immune and acute-phase responses in interleukin-6-deficient mice. Nature 368: 339-342, 1994. 